\title{
Cumulative effect of land use and cover changes in Naoli River basin in Sanjiang Plain on agricultural nonpoint source pollution load
}

\author{
Yu Haibo $^{1} \cdot$ Zhang Le $^{1} \cdot$ Hou Wei ${ }^{1} \cdot$ Wang $\mathrm{Yi}^{1} \cdot \mathrm{Wu}^{1}$ Dan $^{1} \cdot$ Zhang Shuwen $^{2} \cdot$ \\ Bu Kun ${ }^{2}$
}

Received: 5 September 2015 / Accepted: 7 September 2015/Published online: 26 October 2015

(C) Springer International Publishing 2015

\begin{abstract}
Unreasonable land use pattern is the one main driving factor of nonpoint source pollution (NPSP). Based on effect of land use change (reclaiming wetland into cultivated land) on NPSP, this paper analyzed the contents of main forms of nitrogen $(\mathrm{N})$ and phosphorus $(\mathrm{P})$ as well as key climate parameters in Naoli River Basin in Sanjiang Plain through field monitoring, sampling and indoor test. N and $\mathrm{P}$ are major non-point source pollutants. The spatialtemporal variation law of non-point pollution factors under different land use patterns and durations was analyzed. The cumulative effect of long-term land use and cover changes on non-point source pollution was simulated quantitatively by ArcSWAT model. The indoor test reported that (1) paddy field has the higher soil $\mathrm{N}$ and $\mathrm{P}$ contents, followed by dry land, wetland and forest land, successively; (2) in the whole river basin, mid-downstream shows the highest $\mathrm{N}$ and $\mathrm{P}$ nutrients in water, followed by midstream, downstream, mid-upstream and upstream, successively. N and $\mathrm{P}$ distributions in soil are similar to those in water. According to the quantitative simulation of NPSP in the Naoli River Basin, NPSP mainly concentrates on the two sides of the main stream. Compared to forest land, paddy field and dry land contribute more to NPSP. Cultivated land occupies $58 \%$ of the whole basin area, which contributes at least 89.6 and $91.7 \%$ of TP and TN. All of these areas were reclaimed from wetland, indicating that area and spatial position changes of wetland are the main causes of
\end{abstract}

Hou Wei

houwsd@163.com

1 College of Environmental Science, Liaoning University, Shenyang 110036, China

2 Northeast Institute of Geography and Agroecology, Chinese Academy of Sciences, Changchun 130102, China intensifying NPSP in the Naoli River Basin. The cumulative effect analysis revealed that since TN and TP in per unit of cultivated land area increase continuously, land use changes exert cumulative effect on NPSP. In other words, reclamation of wetland will accelerate increase of $\mathrm{TP}$ and TN loads.

Keywords Wetland · Nonpoint source pollution (NPSP) · Land use $\cdot$ SWAT

\section{Introduction}

According to definition of nonpoint source pollution (NPSP) in U.S. EPA Clean Water Act Amendment, pollutants have many diffusion sources and enter into earth surface and groundwater at trace levels (Lee 1977). NPSP has become an important cause of regional water pollution (Werner and Wodsak 1995). America and European countries began to study NPSP as early as in 1960s. They implemented some research programs in areas with heavy NPSP (Lynn 1993; Pegrmm and Bath 1995). Research on NPSP has been focusing on how to employ existing models into NPSP management since 1980s. These models include the SWAT model reflecting NPSP loads in river basins, the AGNPS model for agricultural NPSP control and policy making, the universal soil loss equation (USLE) model, etc. Remote sensing and GIS have been widely used in the quantitative study of NPSP since 1990s, achieving satisfying results (Kinnell 2000; Andrus 1996; Prakash et al. 2000).

Land utilization is closely related to agricultural NPSP. Land use pattern is the key influencing factor of NPSP. Land use changes will change hydraulic characteristics and soil composition of underlying surface, influencing NPSP 
output significantly (Jin et al. 2007). Both Chinese and foreign scholars studied effect of land use pattern and land use changes on NPSP. Peierls analyzed the effects of human activities on nitrogen enrichment (Peierls 1991). Dillon studied the effects of regional geology and land use on phosphorus migration and transformation, finding that land use pattern is important to phosphorus transformation (Dillon and Kirchner 1975). Li studied NPSP output of different land use patterns in Western Zhejiang section of Taihu Lake Basin and Lihe River Basin. He analyzed the statistical relation between land use pattern and runoff. $\mathrm{He}$ established a runoff estimation model and reported COD, BOD, TP and TN output in different lands ( $\mathrm{Li}$ et al. 2004, 2006). Cheng explored nitrogen output characteristics of five typical land use patterns as well as their correlations (Chen et al. 2008). Guo compared $N$ and $P$ outputs of four typical land use patterns in Taihu Lake Basin. He concluded that agricultural land generates the highest TP and TN. He also evaluated the potential level of NPSP in Taihu Lake Basin by combing GIS and agricultural pollution potential index (APPI) (Guo et al. 2004). However, only few researchers studied the cumulative effects of land use changes of NPSP.

\section{Materials and methods}

\section{Study area and land use data analysis}

The Naoli River Watershed $\left(131^{\circ} 31^{\prime}-134^{\circ} 10^{\prime} \mathrm{E}, 45^{\circ} 43^{\prime}-\right.$ $47^{\circ} 35^{\prime} \mathrm{N}$ ) of Heilongjiang province is located in the hinterland of the Sanjiang plain, southeast to Wandashan watershed, connected to the east and the Wusuli River, a total area of $241.67 \mathrm{hm}^{2}$. The administrative divisions in Naoli River Watershed include Baoqing, Fujin, Raohe, Youyi, Jixian and parts of Shuangyashan. Since the 1950s of human reclamation activities, a large area of the wetland in the Naolihe River Basin shrinking which leading to ecological environment worsening condition of the basin. Cultivated land is the primary source of the Naoli River Watershed non-point source pollutants, while the cultivated land was reclaimed from wetlands.

Based on field investigation and TM/MSS (Thematic Mapper pictures of Landsat 5; multi-spectral scanner pictures of Landsat 1-3) images as well as topographic maps, a land use/land cover classification system was established, including dry land, paddy field, woodland and grassland, water, construction land and wetland. This study covered a period of 60 years which was divided into five periods, respectively (1954-1976, 1976-1986; 1986-2000; 2000-2010). Data sources were different in these periods, and processed in different ways as needed. TM satellite remote sensing images were adopted for the period
1986-2010 with a resolution of $30 \times 30 \mathrm{~m}$ per pixel and bands of 4, 3, and 2; in 1976, MSS images were used with a resolution of $80 \times 80 \mathrm{~m}$ per pixel and in 1954 , topographic maps were taken as the data source. TM images of 2010 , and 1986, MSS images of 1976 were corrected based on the data of 2000 and then compared with the images of 2000 , the polygons of changed land use were drawn in order to generate dynamic changing data of the four periods. Since data of 1954 were based on contemporary topographic maps. There was a lot of useful land use/land cover information in topographic maps, such as marshes (passable swamp, impassable bog), sand, saline alkali land, woodland (with a variety of symbols and lines). Finally, land use data of the five periods and a 50-m GRID analysis data were generated by dynamic changing data and data of 1954 and 2010, respectively.

\section{Sample collection}

The research area is in normal flow period from May, June, September and October, but in high-flow period from July to August. During the high-flow period, runoff of farmland and rural domestic wastes are carried by rainfall and runoff into the Naoli River. In this paper, water samples were collected at the small basin outlets of different land use patterns during dry season, normal flow period and high-flow period of the Naoli River. Total nitrogen (TN), total phosphorus (TP), ammonia nitrogen $\left(\mathrm{NH}_{4}{ }^{+}-\mathrm{N}\right)$ and dissoluble phosphorus (DP) were tested. Effect of NPSP on water quality in the Naoli River was analyzed by comparing water sample qualities. The sampling sites include 13 sites during dry season (November 2012), 22 during normal flow period (June 2012), and 16 during highflow period (August 2012). A total of $2000 \mathrm{ml}$ water samples was collected from each sampling site by using water quality analysis sampler. $1000 \mathrm{ml}$ water samples were stored in a vinyl plastic bottle $\left(4{ }^{\circ} \mathrm{C}\right)$ for testing $\mathrm{TN}$ and $\mathrm{NH}_{4}{ }^{+}-\mathrm{N}$. The rest of the $1000 \mathrm{ml}$ water samples were stored in another vinyl plastic bottle $\left(4^{\circ} \mathrm{C}\right)$ for testing TP and DP. Test data were analyzed. Different land use patterns (forest land, grassland, wetland and cultivated land) and durations (10, 30 and 50 years) were surveyed on spot. Corresponding soil samples were collected.

\section{Experimental methods}

Physicochemical properties of collected soil samples and water samples were analyzed. Analysis indexes are TN, $\mathrm{NH}_{4}{ }^{+}-\mathrm{N}$, TP and DP.

$\mathrm{N}$ and $\mathrm{P}$ test in soil: Different forms of $\mathrm{N}$ and $\mathrm{P}$ in collected soil samples were tested through the method in Soil Agricultural Chemistry Analysis (Yao et al. 2011). TN was tested by semi-micro Kjeldahl method. $\mathrm{NH}_{4}{ }^{+}-\mathrm{N}$ was tested by colorimetry. TP was tested by Mo-Sb colorimetry 
after $\mathrm{NaOH}$ fusion. DP was tested by Mo-Sb colorimetry after $\mathrm{NaHCNO}_{3}$ fusion.

$\mathrm{N}$ and $\mathrm{P}$ test in water: $\mathrm{TN}$ was tested by alkaline potassium persulfate digestion $\mathrm{UV}$ spectrophotometric method. $\mathrm{NH}_{4}{ }^{+}-$ $\mathrm{N}$ was tested by Nessler's reagent colorimetry. TP was tested by ammonium molybdate spectrophotometric method. DP was tested by Mo-Sb colorimetry.

\section{SWAT simulation}

Division of hydrologic response unit in upstream of Liao River

Spatial data of SWAT model mainly include digital elevation model (DEM), land use pattern and soil type maps. All input pictures shall be in.grd format and.shp format. These two formats could be converted mutually by ArcGIS9.3. Attribute database for the Naoli River Basin for SWAT simulation was established. Meteorological data include daily precipitation, daily maximum temperature, daily minimum temperature, daily average relative humidity, daily average wind velocity and daily levels of solar radiation.

The SWAT model produces hydrologic response unit (HRU) according to overlapping of soil types and land use patterns in subbasins. It only involves large land use patterns $(>12 \%)$. Every HRU allocated parameters to large ones according to proportions [small lands (area <12\%) were neglected]. It redivides the subbasin into different land use patterns. Similarly, small soil types $(<12 \%)$ were neglected. Based on the overlapping of land use pattern and soil type maps, it divides subbasins into different HRUs. As a result, the 36 subbasins in the research area were divided into 36 HRUs (Fig. 1).

\section{Parameter sensitivity analysis of the SWAT model}

Parameter sensitivity analysis of the SWAT model is to verify whether it is applicable to the Naoli River Basin.

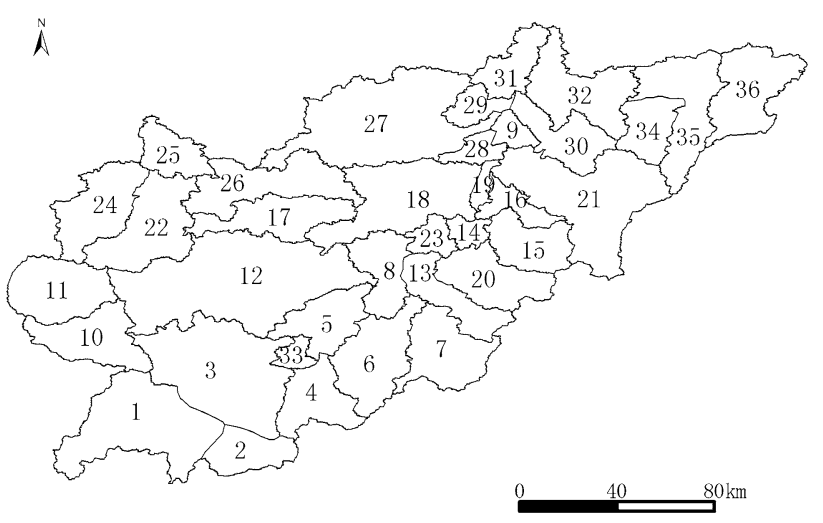

Fig. 1 HRU division of subbasins in the research area
Model parameters were calibrated by SWAT-CUP software. Firstly, parameters were preset, including calibration parameters, simulation times and test data. Subsequently, original parameters of SWAT model were converted into text data and then fed into the SWAT-CUP software. Parameters were simulated and optimized by comparing data of three measurements. Simulated data were compared with measured data to get parameters that contribute reasonable and standard simulated data. Later, parameters were changed and the SWAT model was restarted until getting all running parameters.

\section{Results and discussion}

\section{Spatial-temporal dynamic changes of land use in the Naoli River Basin}

Great land use changes have taken place in the Naoli River Basin from 1954 to 2014 (Fig. 2). Viewed from area proportion, wetland reduces by $4 / 5$ from 45.84 to $9.76 \%$. On the contrary, cultivated land (including paddy field and dry land) increases from 8.20 to $57.97 \%$. Grassland reduces from 15.36 to $4.65 \%$ and forest land reduces from 29.39 to $25.34 \%$. In cultivated land, paddy field increases from 0.09 to $14.91 \%$ and dry land soars to 43.06 from $8.11 \%$. Although paddy field increases continuously, the growth speed slows down. Quickest expansion of paddy field was achieved from 1976 to 1986 . Dry land increases firstly and then reduces after 2000. Construction land increases continuously at a decelerating speed. Quickest expansion of construction land was achieved from 1954 to 1976. Despite small shrinkage in 2008, wetland shrinks at an accelerating speed. Land use changes from 1954 to 2014 were analyzed by using the transfer matrix of land use pattern. A large proportion of paddy land, dry land and construction land was transferred from other land use patterns, while wetland is the prior reclamation object.

The spatial dynamic changes of four greatly changed land use patterns (paddy land, dry land, construction land and wetland) were analyzed by GIS. Wetland shrinks gradually from west to east and from north to south. Existing wetlands are mainly in main stream of Naoli River Basin and National Nature Reserve of Naoli River Basin. Liu studied wetland and other landscape changes in the Naoli River Basin from 1980 to 2000. She pointed out that wetland in the Naoli River Basin changed in stages and wetlands ecosystem degraded gradually. Wetland was fragmented significantly. This is the direct consequence of land use changes caused by rapid economic development (Liu et al. 2002). Hou and Wu studied LUCC in the Naoli River Basin from 1854 to 2000, finding that wetland reclamation into cultivated land is the main LUCC. Such 
Fig. 2 Spatial changes of wetland from 1954 to 2014
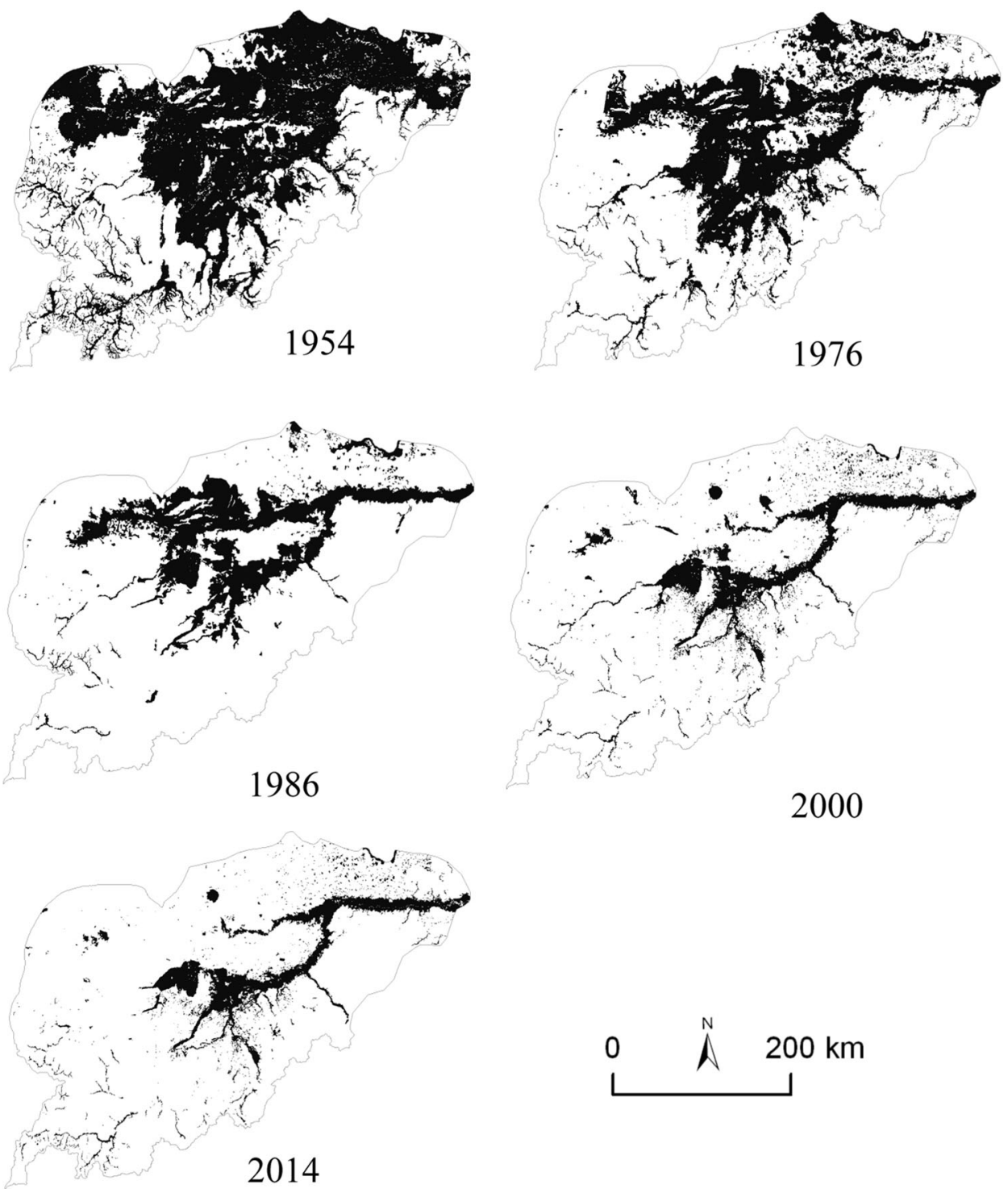

2000

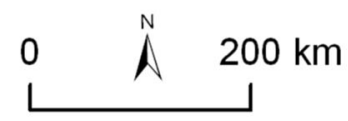

wetland shrinkage is related with reclamation policy to a certain extent (Hou et al. 2006; Wu et al. 2015). Based on same data analysis, Yao concluded that wetlands at different altitudes and slopes were mainly reclaimed into forest land, followed by settlement places, cultivated land, grassland and water areas (Yao et al. 2011). The reclamation process of geomorphic wetlands is from high flood land to river terrace and then to low flood land ( $\mathrm{Li}$ et al. 2000).

\section{$\mathbf{N}$ and $\mathbf{P}$ changes in soil of different land use patterns}

\section{TN changes}

Soil samples collected from the Naoli River Basin contain $1.25-3.38 \mathrm{~g} / \mathrm{kg} \mathrm{TN}(2.26 \mathrm{~g} / \mathrm{kg}$ in average). According to China's second soil survey data, nitrogen content in cultivated soil ranges between 0.4 and $3.8 \mathrm{~g} / \mathrm{kg}$ (about $1.3 \pm 0.5 \mathrm{~g} / \mathrm{kg}$ in average) (Richard 1982) and the average nitrogen content in natural surface soil (except for desert soil and surface corroded soil) is about $2.9 \pm 1.5 \mathrm{~g} / \mathrm{kg}$, mainly within $0.4 \pm 7.0 \mathrm{~g} / \mathrm{kg}$ (Sernells 2001). This indicates that TN in soil in the Naoli River Basin agrees with general soil conditions in China. Soil in the Naoli River Basin has high fertilization. In the whole basin, midstream shows higher TN compared to rest places. Besides, paddy field shows the highest TN, followed by dry land, wetland and forest land successively.

\section{TP changes}

Soil samples collected from the Naoli River Basin contain 435-1143 mg/kg TP (962 mg/kg in average). Lu Rukun pointed in principle of soil-plant nutrition and fertilization 
that TP in soil ranges between 200 and $5000 \mathrm{mg} / \mathrm{kg}(500 \mathrm{mg} /$ $\mathrm{kg}$ in average) in the word and $200-1100 \mathrm{mg} / \mathrm{kg}$ in China (Peierls 1991). Therefore, TP in the Naoli River Basin is slightly higher than China's average level, but still conforms to China's overall situations. In the Naoli River basin, midstream has higher TP compared to rest places. Moreover, paddy field shows the highest TP, followed by dry land, wetland and forest land successively. Particularly, TP in paddy field, dry field, wetland and forest land in midstream drops sharply. Places with frequent human activities, longer reclamation years and higher fertilization have more serious pollutants enrichment and poorer soil quality. Thomas M. Burton et al. discussed $\mathrm{N}$ and $\mathrm{P}$ output law in cultivated land that has been abandoned for 15-20 years in the Great Lakes Basin. Cultivated land abandoned for 18 years output significantly lower $\mathrm{N}$ and $\mathrm{P}$ than adjacent cultivated lands (Ning et al. 2006). Li studied correlation between land use patter and surface water quality in the Yuqiao Reservoir Basin at upstream of Jiyun River. He reported that among basins with single land use pattern, small basins of forest land and grassland enjoy far better surface water quality than that of cultivated land. Additionally, NPSP in small basins is inversely proportional to area of forest land and grassland, but proportional to area of cultivated land (Li et al. 2000).

\section{$\mathbf{N}$ and $\mathbf{P}$ changes in water in the Naoli River Basin}

\section{TN changes}

$\mathrm{TN}$ in water ranges between 0.92 and $10.61 \mathrm{mg} / \mathrm{l}$. The highest TN was detected in artificial channel and the lowest TP was detected in upstream of the Naoli River. The higher $\mathrm{TN}$ in artificial channel is mainly caused by intensive human activities. The average $\mathrm{TN}$ of rest water samples was tested $1.65 \mathrm{mg} / \mathrm{l}$. According to GB3838-2002, water in upstream of the Naoli River and upstream Baoshi River reached III grade; water in Jiansanjiang Economic Development Zone, Qixing Farm, Shengli Farm, artificial channels and downstream Baoshi River is evaluated $\mathrm{V}$ and even VI grade; water in rest areas is IV and V grade. Figure 3 shows TN distribution in the whole Naoli River Basin. Midstream, especially the mid-upstream, shows higher TN. Generally, TN increases gradually from upstream to downstream. This is related to developed agriculture in mid-upstream, midstream, and mid-downstream.

\section{TP changes}

$\mathrm{TP}$ in water ranges from 0.03 to $0.36 \mathrm{mg} / \mathrm{l}(0.19 \mathrm{mg} / \mathrm{l}$ in average). The highest TP was detected in the artificial channel, while the lowest TP was detected in mid-upstream Youyi River. Comparatively, the Naoli River Basin was bearing heavy phosphorus loads. The rest of the water samples were tested and were of inferior $\mathrm{V}$ grade. It can be known from Fig. 4 that mid-upstream and mid-downstream have higher TP than other places. TP shows a similar normal distribution in the Naoli River Basin.

\section{Coupling analysis on water-land $N$ and $P$ changes}

In the data sheet, lands with longer reclamation years have higher $\mathrm{N}$ and $\mathrm{P}$ contents. It can be seen from Figs. 3 and 4 that mid-downstream suffers the heaviest soil pollution, followed by midstream, downstream and upstream. This is similar to pollutant contents in water samples, reflecting pollutant sources in water to a certain extent. The average TN in Naoli River is $4.54 \mathrm{mg} / \mathrm{L}$ during the high-flow period, but only $2.6633 \mathrm{mg} / \mathrm{L}$ during the normal flow period.
Fig. $3 \mathrm{TN}$ in collected water samples

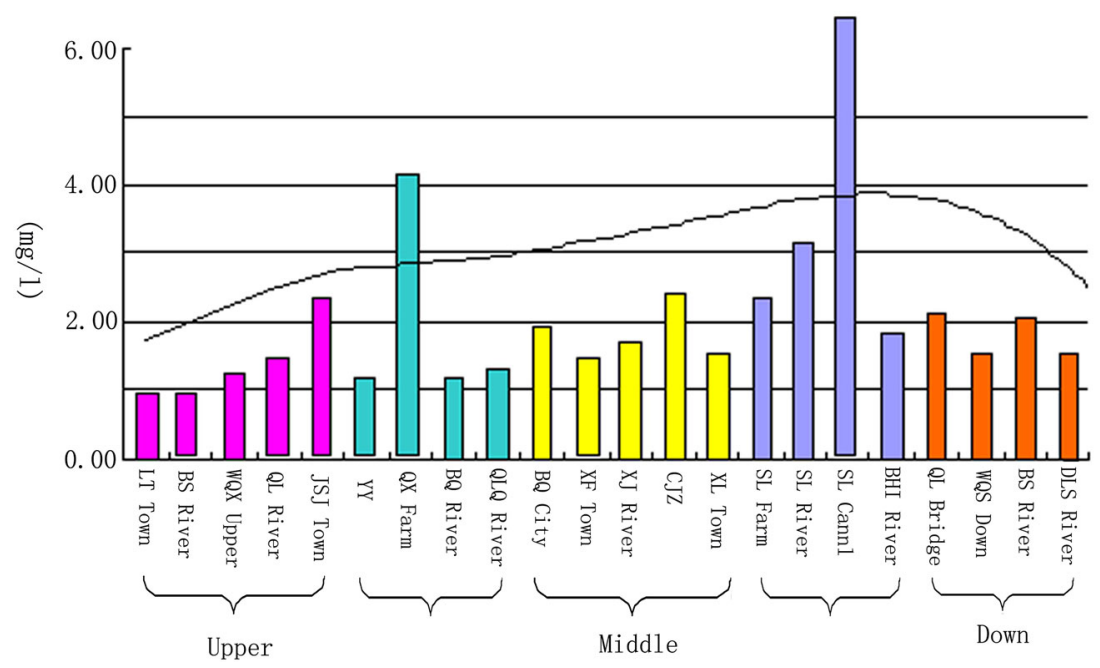


Fig. 4 TP in collected water samples

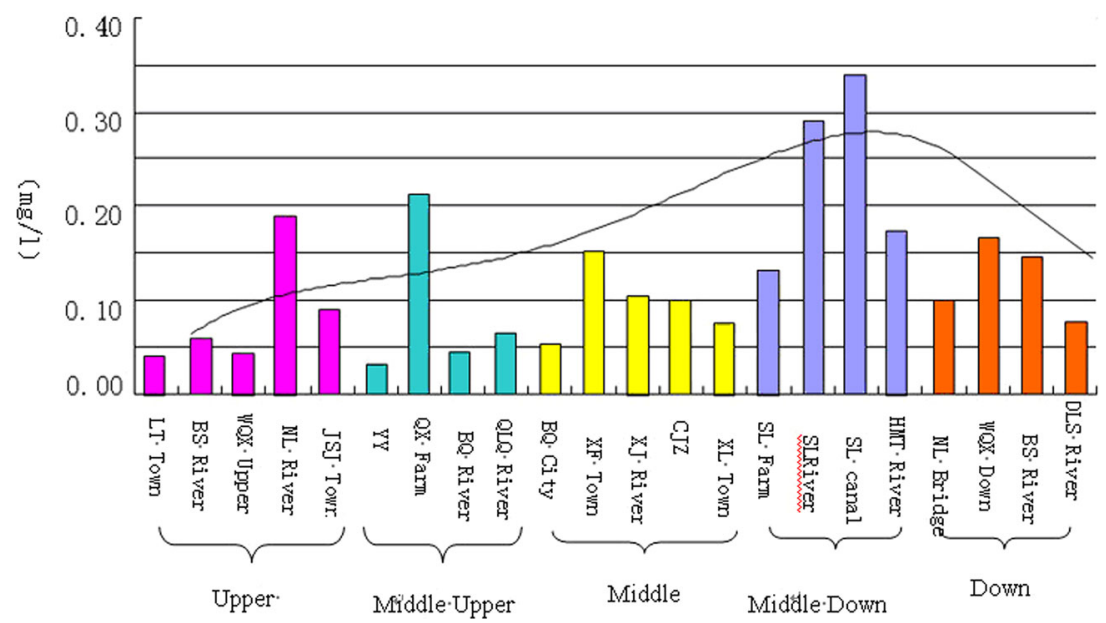

The Naoli River has relatively better water quality during the normal flow period, but excessive TN during high-flow period. This is caused by import of farmland runoff and rural domestic wastes. Therefore, $\mathrm{N}$ in the Naoli River mainly comes from NPSP in the Naoli River Basin. To sum up, land uses changes (especially farmland area and scope) in the Naoli River Basin will influence TN in water significantly.

\section{Quantitative analysis on NPSP load}

Based on land use data in 2014, N and P loads during highflow period, normal flow period and dry season in the Naoli River Basin were simulated by the calibrated and verified SWAT model. Simulated HRU division was exported in text files and then imported into the ArcGIS software to get spatial distributions of TP and TN during three study periods. With TP and TN data in HRU as well as land use patterns in different HRUs in 2014, the relationship between land use structure and NPSP load was analyzed. Key attention was paid in comparison of NPSP loads in paddy field, dry land, forest land and wetland. On this basis, the quantitative relationship between land use pattern and NPSP load in HRU was established. Spatial distribution characteristics of TN and TP in the Naoli River Basin during different periods were calculated from algebraic operation in ArcGIS software (Fig. 5). NPSP load in the Naoli River Basin mainly concentrates on two sides of the main stream. Compared to forest land, paddy field and dry land contribute more to NPSP. Cultivated land occupies $58 \%$ of the whole basin area, which contributes at least 89.6 and $91.7 \%$ of TP and TN. Furthermore, paddy field and dry land are the main sources of NPSP load in the Naoli River Basin.

\section{Cumulative effect of land use dynamic changes on NPSP}

Based on N and P loads in 2014, N and P loads in HRU of paddy field, dry land, wetland and forest land in 1954, 1976, 1986 and 2000 were simulated by SWAT model. The SWAT simulation used different land use data, but assumes that DEM and soil type remained unchanged. Simulation results are listed in Table 1. There is a negative correlation but not linear relationship between NPSP load and wetland area.

Based on TP and TN data in HRU and land use pattern in different HRUs in 2010, the relationship between land use structure and NPSP load was analyzed. Key attention was paid to analyze NPSP load changes caused by wetland area changes. NPSP load in the Naoli River Basin mainly concentrates on two sides of main stream. Compared to forest land, paddy field and dry land contribute more to NPSP. Cultivated land occupies $58 \%$ of the whole basin area, which contributes at least 89.6 and $91.7 \%$ of TP and TN. Paddy field and dry land are the main sources of NPSP load in the Naoli River Basin. These areas were reclaimed from wetland, indicating that area and spatial position changes of wetland are the main causes of intensifying NPSP in the Naoli River Basin. This paper concluded that the correlation coefficient between wetland area changes and $\mathrm{TN}$ is -0.98 , and the correlation coefficient between wetland area changes and $\mathrm{TP}$ is -0.99 . The cumulative effect analysis demonstrated that TN and TP in per unit of cultivated land increase continuously. This means that land use changes have cumulative effect on NPSP. In other words, reclamation of wetland will accelerate increase of TP and TN loads. 

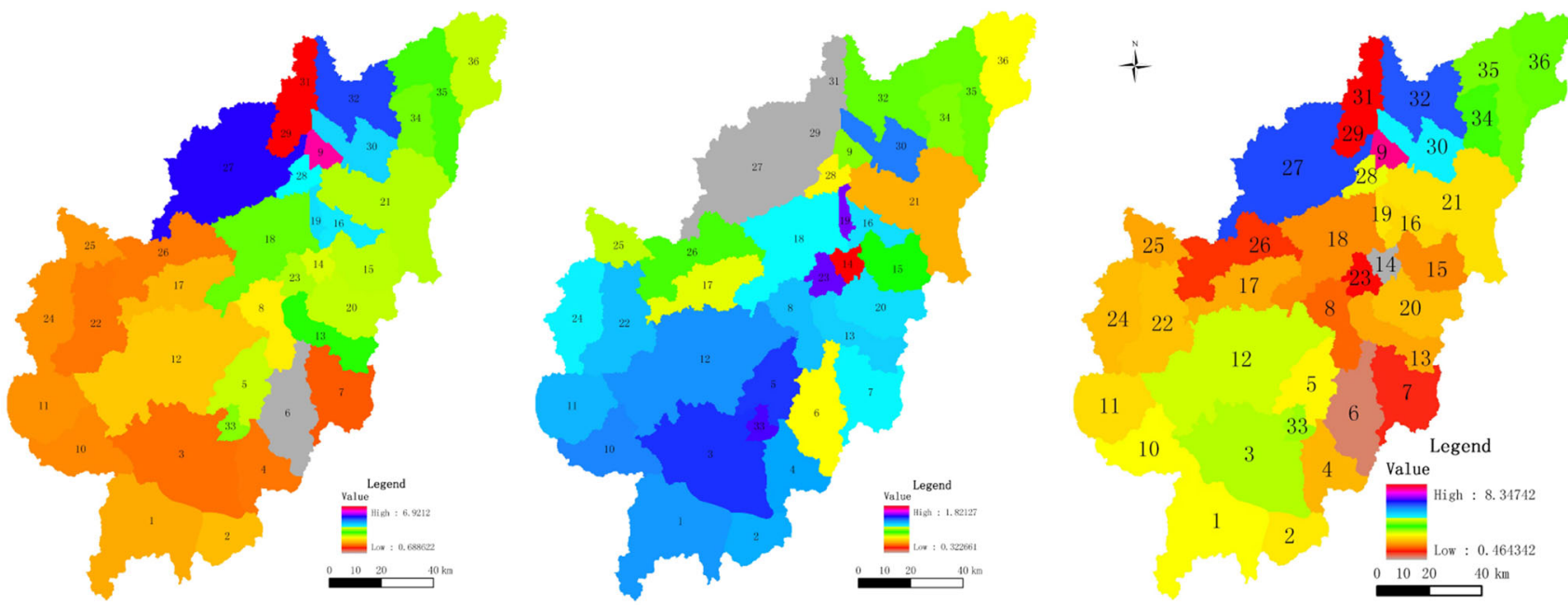

TN load during abundant water, normal flow and low water period
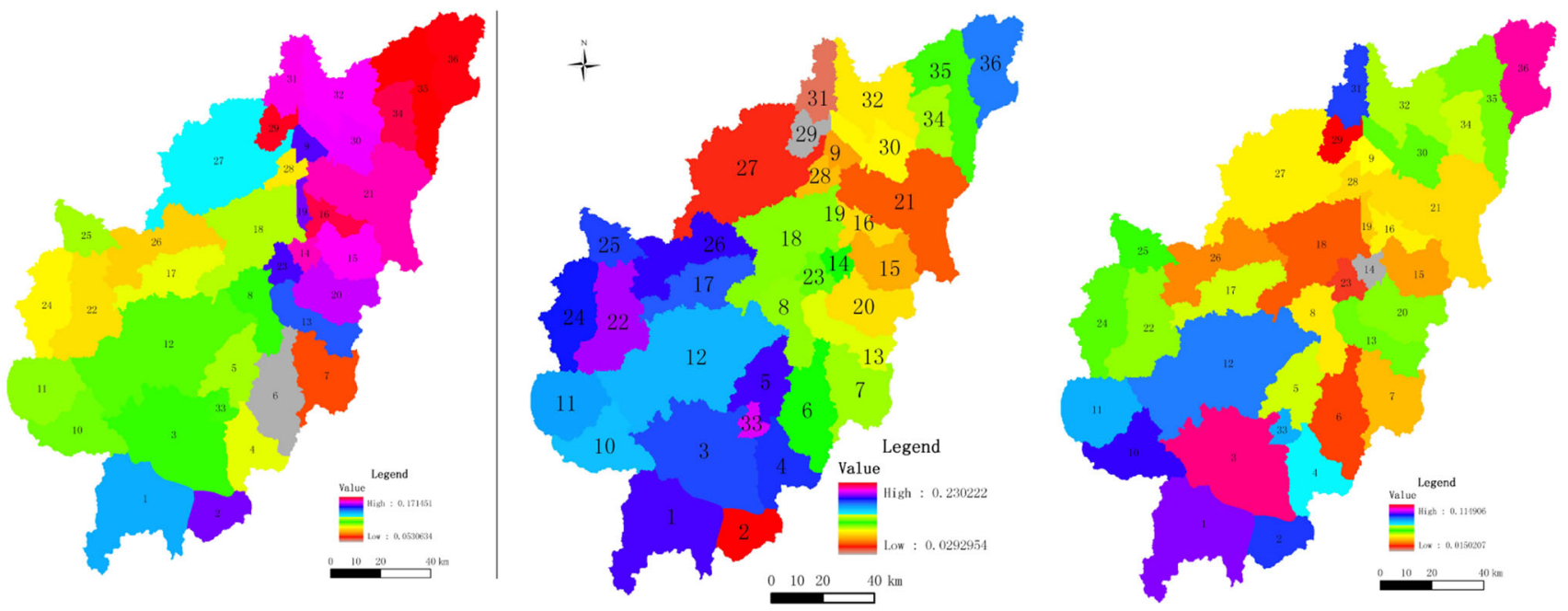

\section{TP load during abundant water, normal flow and low water period}

Fig. 5 TP load during abundant water, normal flow and low water period

Table 1 Land use changes from 1954 to $2014\left(\mathrm{~km}^{2}\right)$

\begin{tabular}{lrrrrr}
\hline & \multicolumn{1}{c}{1954} & \multicolumn{1}{c}{1976} & \multicolumn{1}{c}{2000} & \multicolumn{1}{c}{2014} \\
\hline Paddy field & 23.56 & 17.05 & 1957.35 & 3218.46 & 3736.07 \\
Dry land & 2033.08 & 6846.17 & $10,143.68$ & $11,167.86$ & $10,789.28$ \\
Construction land & 61.43 & 263.60 & 392.78 & 383.00 & 424.33 \\
Wetland & $11,486.33$ & 7565.60 & 4550.30 & 2775.60 & 2445.47 \\
TN & $521,704.10$ & $1,507,724.02$ & $3,087,324.71$ & $3,389,255.83$ & $3,825,872.83$ \\
TP & $81,980.77$ & $280,275.38$ & $499,436.53$ & $609,421.43$ & $635,503.76$ \\
\hline
\end{tabular}

\section{Conclusions}

1. Among different land use patterns, paddy field contains the highest $\mathrm{N}$ and $\mathrm{P}$ in soil, followed by dry land, wetland and forest land, successively. In the whole Naoli River Basin, mid-downstream shows the highest $\mathrm{N}$ and $\mathrm{P}$ contents in water, followed by midstream, downstream, mid-upstream and upstream, 
successively. $\mathrm{N}$ and $\mathrm{P}$ distributions in soil are similar to those in water.

2. The NPSP load in the Naoli River Basin mainly concentrates on two sides of the main stream, where there were wetlands before 1954. This indicates that area and spatial position changes of wetland are the main causes of intensifying NPSP in the Naoli River Basin.

3. Land use changes have cumulative effect on NPSP. In other words, reclamation of wetland will accelerate increase of TP and TN loads.

Acknowledgments This research is supported by NSFC (Natural Science Foundation of China (31100349).

\section{Compliance with ethical standards}

Conflict of interest The authors declare that they have no conflict of interest. This article does not contain any studies with human participants or animals performed by any of the authors. Informed consent was obtained from all individual participants included in the study.

Ethical statement The authors certify that this manuscript is original and has not been published and will not be submitted elsewhere for publication while being considered by Ecological Engineering. The submission has been received explicitly from all co-authors. In addition, authors whose names appear on the submission have contributed sufficiently to the scientific work and therefore share collective responsibility and accountability for the results.

\section{References}

Andrus M (1996) Integration of gis and a dynamic spatially distributed model for non-point source pollution management. Water Sci Technol 33(4-5):211-218

Chen HG, Hao Fanghua, Ren Xiyan (2008) Loss coefficient of nitrogenous non-point source pollution under various precipitation conditions. Front Environ Sci Eng China 2(2):49-53

Dillon PJ, Kirchner WB (1975) The effects of geology and land-use on the export of phosphorus from watersheds. Water Resour 9:135-148

Guo HY, Wang XR, Zhu JG (2004) Quantification and index of nonpoint source pollution in Taihu Lake region with GIS. Environ Geochemist Health 26:147-156
Hou W, Kuang WH, Zhang SW, Zhang YZ, Li Y (2006) Analysis of cultivated land reclamation process and the ecological effects in north of Sanjiang Plain from 1950's. Ecol Environ 15(4):324-330

Jin Y, Li HP, Li JL (2007) The impact of non-point pollutant load of land-use changes in Taihu Basin. J Agro-Environ Sci 26(4): $1214-1218$

Kinnell PIA (2000) AGNPS-UM: applying the agricultural non point source pollution model. Environ Model Softw 15(3):331-341

Lee SI (1977) Nonpoint source pollution. Fisheries 2:50-52

Li JR, Chen LD, Guo DX (2000) Effects of landuse structure on nonpoint source pollution. Chin Environ Sci 20(6):506-510

Li HP, Liu XW, Huang WY (2004) The non-point output of different agriculture landuse types in Zhexi hydraulic region of Taihu Basin. J Geogr Sci 59(3):401-408

Li HP, Huang WY, Yang GS (2006) Non-point pollutant concentrations for different land uses in Lihe River watershed of Taihu Region. Chin Environ Sci 26(2):243-247

Liu HY, Zhang SK, Lv XG (2002) Processes of wetland landscape changes in Naoli River Basin since 1980s. J Nat Resour 17(6):698-705

Lynn RS (1993) Non-point source programs and progress in the Chesapeake Bay. Agric Ecosyst Environ 46(1-4):217-222

Ning SK, Chang NB, Deng KY (2006) Soil erosion and non-point source pollution impacts assessment with the aid of multitemporal remote sensing images. J Environ Manage 79:88-101

Pegrmm GC, Bath AJ (1995) Role of non-point sources in the development of a water quality management plan for the Mgeni river catchment. Water Sci Technol 32(5-6):175-182

Peierls BL (1991) Human influence on river nitrogen. Nature 350:386-387

Prakash B, Teeter LD, Lockaby BG, Flynn KM (2000) The use of remote sensing and GIS in watershed level analyses of non-point source pollution problems. For Ecol Manage 128(1-2):65-73

Richard FH (1982) Inferring non-point pollution from land cover analysis. Adv Space Res 2(8):201-208

Sernells S (2001) Priority of questions for land use cover change research in the next couple of years. LUCC newsletter no. 7

Werner W, Wodsak HP (1995) The role non-point nutrient sources in water pollution-present situation, countermeasures, outlook. Water Sci Technol 31(8):87-97

Wu D, Hou W, Zhang SW, Bu K, Xiang B, Wang Y, Li Y (2015) Processes and prediction of land use/land cover changes(LUCC) driven by farm construction: the case of Naoli River Basin in Sanjiang Plain. Environ Earth Sci 73:4841-4851

Yao YL, Lv XG, Yu HX (2011) Influence factors of wetland cultivation in Naoli River watershed of Sanjiang Plain. J Northeast For Univ 39(1):72-74 